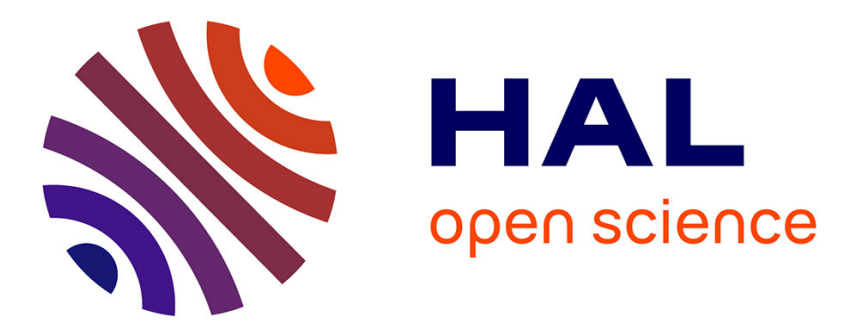

\title{
Effect of continuous strain path changes on forming limit strains of DP600
}

\author{
Xiao Song, L. Leotoing, Dominique Guines, Eric Ragneau
}

\section{To cite this version:}

Xiao Song, L. Leotoing, Dominique Guines, Eric Ragneau. Effect of continuous strain path changes on forming limit strains of DP600. Strain, 2019, 55 (6), 10.1111/str.12329 . hal-02328681

\section{HAL Id: hal-02328681 \\ https://hal.science/hal-02328681}

Submitted on 23 Oct 2019

HAL is a multi-disciplinary open access archive for the deposit and dissemination of scientific research documents, whether they are published or not. The documents may come from teaching and research institutions in France or abroad, or from public or private research centers.
L'archive ouverte pluridisciplinaire HAL, est destinée au dépôt et à la diffusion de documents scientifiques de niveau recherche, publiés ou non, émanant des établissements d'enseignement et de recherche français ou étrangers, des laboratoires publics ou privés. 


\title{
Effect of continuous strain path changes on forming limit strains at necking and fracture of DP600 sheets
}

\author{
X. Song, L. Leotoing, D. Guines, E. Ragneau \\ Univ Rennes, INSA Rennes, LGCGM - EA 3913 \\ F-35000 Rennes, France
}

\begin{abstract}
The strain path may change in actual sheet metal forming processes, so the determination of formability of sheet metal should consider the non-linear strain path. For identifying the forming limit (FL) strains under non-linear strain path, a conventional two-step procedure with unloading is classically used to produce the strain path change, which results in no continuous measure of strain. The in-plane biaxial tensile test with a cruciform specimen is an interesting alternative to overcome the drawbacks of conventional method. The strain path change can be made without unloading during a single test. In this work, the experimental FL strains of DP600 sheets under two types of non-linear strain path are investigated and then compared with those under linear strain paths. The Oyane ductile fracture criterion is used in the finite element simulation to predict the experimental results.
\end{abstract}

Keywords: In-plane biaxial tensile test, FLCN, FLCF, non-linear strain path

\section{Introduction}

Most of the forming limit curves at necking (FLCNs) and the forming limit curves at fracture (FLCFs) have been experimentally determined using methods that produce proportional loading with insignificant changes in strain paths. However, in some innovative forming processes, such as single point incremental forming, complex strain paths with several changes have been identified by different authors. As an example, the figure 1 shows the evolution of the strain path during an incremental forming operation of a truncated aluminium cone with a wall angle of $60^{\circ}$ [1]. As can be seen, drastic changes in the strain path are observed during the forming operation, without unloading, and a very high level of deformation can be achieved, well beyond the conventional forming limit strains at necking. In addition, it has been demonstrated that strain path change has an influence on the FLCN and more specifically on the high level of forming limits (FL) [2].

Because the strain path change obviously affects the FL strains at necking, no unified FLCN exists in the strain space to represent the formability of sheet metal [3]. The strain paths in sheet metal forming are classically divided into two types: linear strain path and non-linear strain path. Traditionally, the identification of strain-based FLCN or FLCF is limited to the sheet metal undergoing linear strain paths. Three types of experimental FLCN (Figure 2) are concluded by Barata et al. [2] to investigate the effect of strain path change on the FL strains at necking. For type 1, the FLCN is determined under proportional loading. Every point of the FLCN is defined by major and minor strains at necking. As shown in Figure 2 (a), the whole FLCN (ABCD) is

*corresponding author, lionel.leotoing@insa-rennes.fr 
produced by different strain paths from biaxial stretching (OA) to uniaxial tension (OD) through plane-strain tension (OC). The red dash line shows the FLCF, which is higher than the FLCN [4]. For type 2, the FLCN is identified under two steps of proportional loading. Different prestrain levels under a constant strain ratio P1 are used, and then an abrupt change is produced towards the strain ratio P2 for every prestrain level. As shown in Figure 2 (b), the curve ABCD is identified by the uniaxial prestrain followed by biaxial stretching, and the curve AEFD is produced by different levels of biaxial prestrain followed by uniaxial tension. For type 3 , the FLCN is also determined under two steps of proportional loading. The strain path and strain level are kept constant in the first step, and different strain paths are used in the second step. As shown in Figure 2 (c), the biaxial stretching is followed by various ratios of linear strain path for the curve $A B C D$, while the uniaxial tension is followed by different ratios of linear strain path for the curve EFGH.

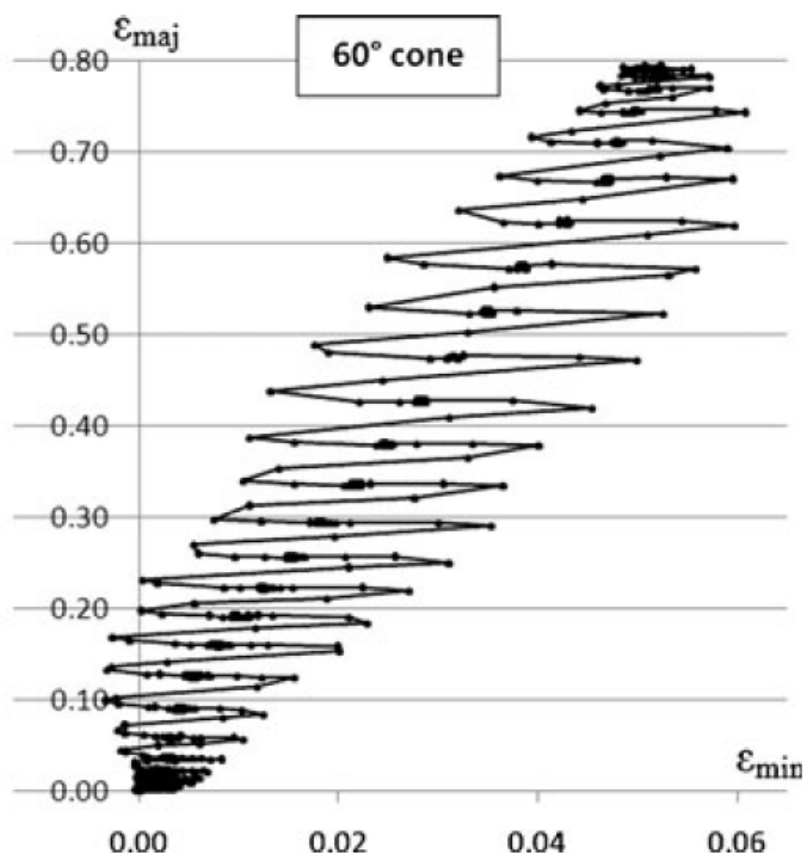

Figure 1: Evolution of the major and minor surface strains for a $60^{\circ}$ wall angle cone during incremental forming process [1]

The strain path change is always produced by a two-step procedure in conventional tests to identify the experimental FLCN under non-linear strain paths. In the first step, oversized specimen is produced by the tensile test, Marciniak or bulge test to obtain prestrains in uniaxial tension, plane-strain tension or biaxial stretching. In the second step, the oversized pre-strained sheet is deformed under new loading condition in order to achieve a strain path change. Ishigaki [5] at Toyota Motors Company have applied the multi-stage loading to increase the formability of sheet metal. The engineers firstly used four stages of prestrain in uniaxial tension to reach $37 \%$ of major strain. Whereafter, two stages of biaxial stretching were adopted which dramatically improved the formability. Graf and Hosford [6] have investigated the influence of strain path change on the FL at necking of aluminum alloy 6111-T4. Different prestrain levels in various loading conditions are considered for the FLCNs. The results show that the abrupt change of strain path can significantly affect the FL at necking. The prestrain in biaxial stretching decreases the level of FL strain if succeeded by uniaxial tension or planestrain tension. The prestrain in uniaxial tension increases the level of FL strain if succeeded by biaxial stretching 


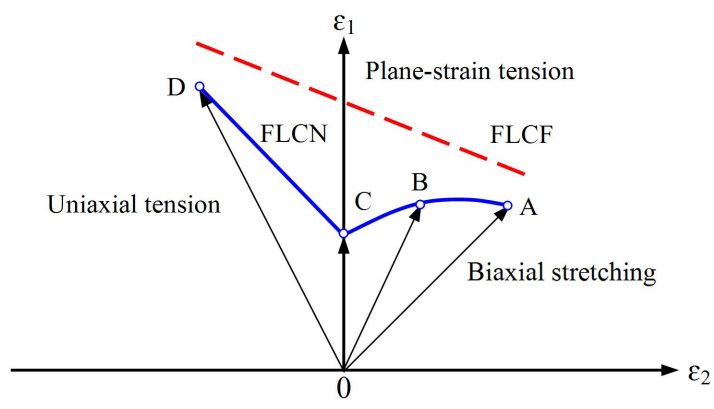

(a) Type 1 (linear strain path)

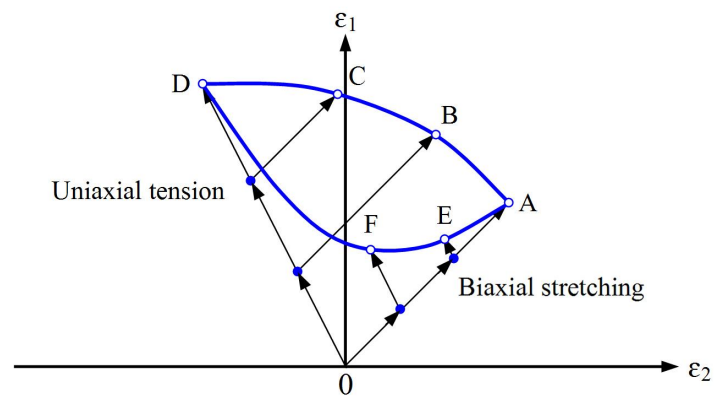

(b) Type 2 (non-linear strain path)

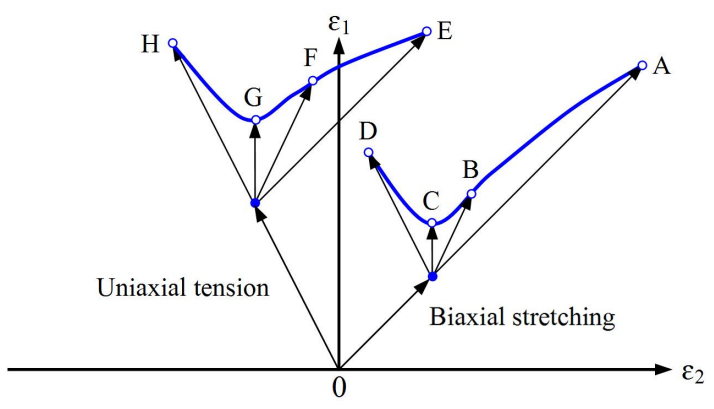

(c) Type 3 (non-linear strain path)

Figure 2: Three types of experimental FLCN

and plane-strain tension, when the direction of principal strain is maintained but decreases if the direction of principal strains is changed after the prestrain. The prestrain in plane-strain tension leads to a small increase of the level of FLCN when the principal strain direction is maintained, but a substantial decrease is happened with the change of principal strain direction. Stoughton et al. [7] have analyzed the FLCNs for 2008-T4 sheet metal under different prestrains reported by Graf and Hosford [8] in early years. Recently, Volk et al. [9] have adopted the two-step procedure to plot experimental FLCN of a high strength steel HC300X under non-linear strain paths and six different prestrains from uniaxial to equibiaxial are considered. In addition, the experimental results of two-step procedure have been widely used for comparison with numerical results in many predictive researches $[10,11,12]$. To represent the formability of metallic sheets under non-linear strain paths, the stress-based forming limit concept was proposed in the early 1980s [13]. It is found that the forming limit stress curve (FLSC) is almost path-independent [3]. Many authors [14, 15, 16] have investigated the FLSC but the main disadvantage of this approach is that the stress state cannot be measured experimentally. The FLSC is calculated from the measured forming limit strains using postulated constitutive behaviours, i.e. yield function and hardening rule.

Some disadvantages can be found in the conventional two-step procedure for controlling the strain path. Firstly, the conventional method requires different experimental methods to obtain different strain paths. Secondly, the unloading between two steps is obligatory and no continuous measure of strain is produced, while non-linear strain paths are observed without any unloading in some forming processes (like single point incremental forming process [1]). Thirdly, multiple strain path changes are impossible. Only simple prestrains can be realized which makes difficult to study the formability with several changes of strain path. Using the in-plane biaxial tensile test with the cruciform specimen to control the strain path can be an interesting alternative to overcome the drawbacks of conventional methods. The potentiality of the in-plane biaxial tensile test 
with a cruciform specimen to study the effect of strain path change on the FLCN and to investigate the FLCF under linear strain paths was validated by the presenting authors [17, 4]. Firstly, the strain path during the test can be directly controlled by the motion of actuators along the two axes, which is sufficient to cover the whole forming limit diagram under linear and non-linear strain paths. Secondly, the unloading is not obligatory and the measurement of strain is continuous during strain path changes. Lastly, complex strain path with several changes can be envisaged for continuous process conditions (temperature, strain rate). For the in-plane biaxial tensile test, the critical point remains the design of the cruciform specimen. A high number of cruciform shapes have been proposed in literature, depending on the mechanical behavior to be studied: yield locus, hardening, forming limits ... Recently, a standardized shape, based on the works of Kuwabara et al. [18] has been proposed. However, this shape is not suitable for forming limit investigations. Strains are very low in the central area and fracture takes place in the arms. A first geometry made from a metal sheet with an initial thickness of $4 \mathrm{~mm}$ was validated for the determination of FLCN and FLCF [4] for AA5086. For linear strain paths, the correlation between results from conventional Marciniak tests and biaxial tensile tests is rather good for FLCN [19]. Recently, a new shape with an initial thickness of $2 \mathrm{~mm}$ was optimized by the authors and validated for linear strain paths [20]. The initial thickness reduction from $4 \mathrm{~mm}$ to $2 \mathrm{~mm}$ permits to study metal sheets with a larger range of applications. For the two geometries, a thickness reduction is necessary in the central region and slits on arms reduce transverse rigidity and strain localization in the junction area of two perpendicular arms.

A predictive method can cover a wide range of linear and non-linear strain paths, which is easier and cheaper than experimental determination [10]. In the literature, most of the studies for prediction of FL under non-linear strain path are investigated with the M-K model. Graf and Hosford [21] have analyzed the effect of abrupt and gradual changes of strain path on FLCN of aluminum alloy 2008-T4 by using the M-K model. The FLCN moves to the right and down compared with the original FLCN when the first step corresponds to biaxial stretching, while it moves to the left and up when the uniaxial tension is adopted in the first step. Yoshida et al. [3] have analyzed the influence of strain path change on the FL stresses of sheet metals by using the M-K model. Two types of loading are considered: one type has unloading between two steps of loading while the other one has no unloading. The results show the strain path has influence on the FL in strain space, while the FL in stress space depend on the strain path only for the second type of loading. Kuroda and Tvergaard [22] have investigated the effect of strain path change on the FLCN by using the M-K model. The predictive results show that FLCN depends on the unloading between the two steps of loading. The elastic straining is very important for the dependence. When the unloading is adopted between the two steps, the stress point of yield surface moves in a different way, which leads to a different flow localization response. Chow et al. [10] have extended an anisotropic damage model to predict the FLCNs of AA6111-T4 sheet under non-proportional loading. The prestrains in uniaxial tension, plane-strain tension and biaxial stretching are considered. The second loading direction is parallel or perpendicular to the first loading direction. The investigation of the damage model is made by comparing the calculated results of FLCN with the experimental results published by Graf and Hosford [6]. When the first and second loading direction are parallel, the correlation between the predictive FLCN and the experimental result is good. However, the predictive FLCN is lower than the experimental FLCN when the two loading directions are perpendicular.

Isik et al. [23] have analyzed the FLCF by a theoretical method. Based on the damage mechanics and the correlation between FLCF and fracture toughness, the authors have concluded that the FLCF is a straight line. On the contrary, the FLCN is not a material property and is strain path dependent. In addition, the linear profile of FLCF is validated experimentally under linear strain paths, while non-linear strain paths are not considered.

In this study, the in-plane biaxial tensile test is used to investigate the FL strains at necking and fracture of 
DP600 sheet metal under two types of non-linear strain paths. A ductile fracture criterion for predicting the onset of fracture under non-linear strain paths will also be discussed.

\section{Experimental procedure and results}

\subsection{Cruciform specimen}

As shown in Figure 3, an optimized cruciform specimen was proposed by the authors to identify the FL strains at fracture of DP600 sheets under linear strain paths [20]. This specimen is designed for sheets with an initial thickness of $2 \mathrm{~mm}$ and the shape is not specific to DP600 sheets since its performance was also validated for other materials, like aluminium alloys. For generating strain localization in the central area of the specimen (fracture zone), a circular arc profile is adopted in the thickness direction of the circular reduced zone and six slots with an optimized arrangement are used. The strain path in the central area of the specimen can be controlled directly by four independent actuators.

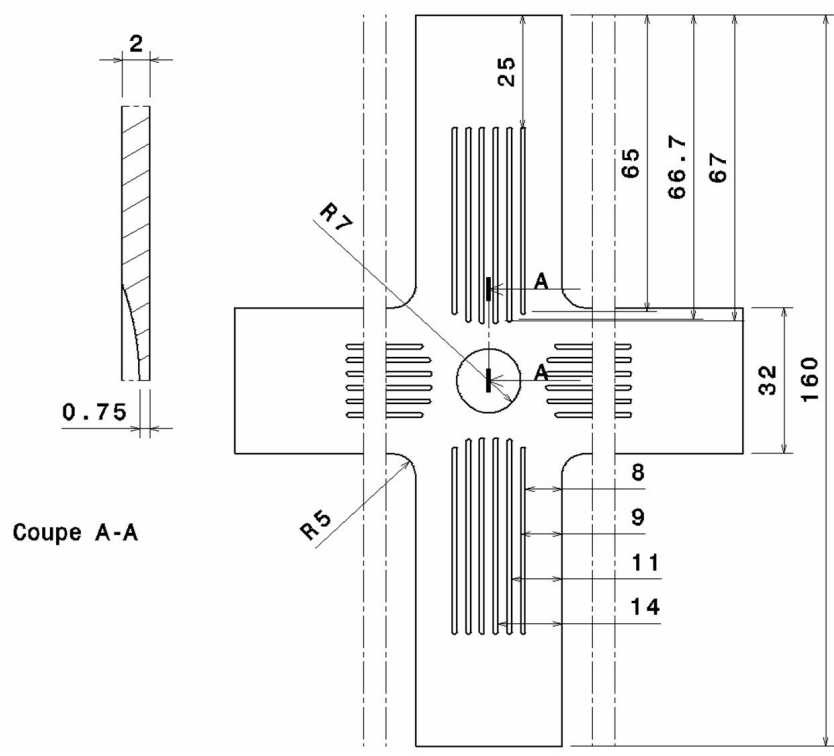

Figure 3: Geometry of the cruciform specimen [20]

As shown in Table 1, different linear strain paths including equibiaxial stretching, plane-strain tension and uniaxial tension are produced by different velocity ratios of actuators acting on the arms of cruciform specimen.

Table 1: Different velocity ratios of actuators for producing linear strain paths

\begin{tabular}{cccc}
\hline Velocity ratio R & $\mathbf{1}$ & $\mathbf{0 . 0 5}$ (plane-strain tension) & uniaxial tension \\
\hline Velocity along axis X (mm/s) & 1 & 2 & 1 \\
\hline Velocity along axis Y (mm/s) & 1 & 0.1 & free \\
\hline
\end{tabular}

As shown in Figure 4, two types of non-linear strain paths are considered in this work. For the type 2-A, two steps of loading without unloading are used, in which the first step corresponds to the uniaxial tension and 
the equibiaxial stretching is used for the second step. For the type 2-B, the first step corresponds to equibiaxial stretching and the plane-strain tension is adopted for the second step. As shown in Table 2, five levels of displacement in uniaxial tension for the type 2-A and six levels in equibiaxial stretching for the type 2-B are considered in the first step.

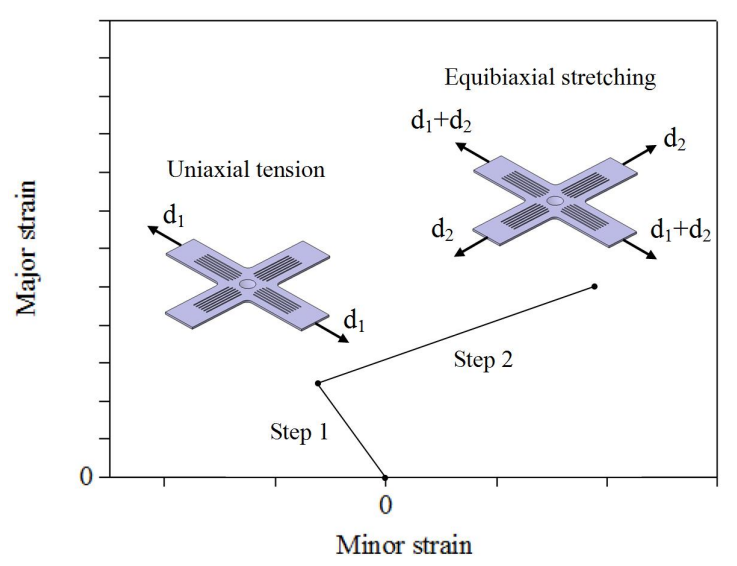

(a) Type 2-A

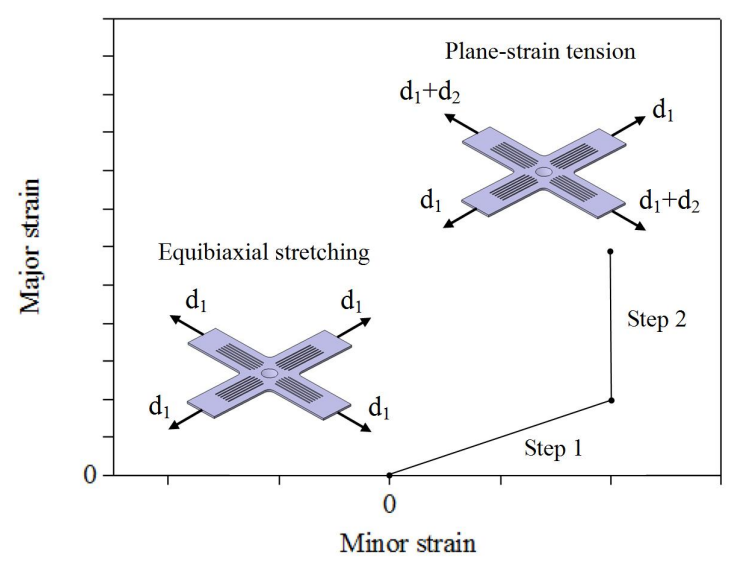

(b) Type 2-B

Figure 4: Two types of non-linear strain path [24]

Table 2: Different displacements in step 1 of non-linear strain paths

\begin{tabular}{cc}
\hline Type 2-A & Type 2-B \\
\hline $2.0 \mathrm{~mm}$ & $2.0 \mathrm{~mm}$ \\
\hline $2.5 \mathrm{~mm}$ & $2.5 \mathrm{~mm}$ \\
\hline $3.0 \mathrm{~mm}$ & $3.0 \mathrm{~mm}$ \\
\hline $3.5 \mathrm{~mm}$ & $3.5 \mathrm{~mm}$ \\
\hline $4.0 \mathrm{~mm}$ & $4.0 \mathrm{~mm}$ \\
\hline- & $4.5 \mathrm{~mm}$ \\
\hline until fracture & until fracture \\
\hline
\end{tabular}

One can see on figure 3 that the thickness reduction in the center is obtained by removing material from one side only. The opposite side of the specimen is plane. This plane surface is used to generate the speckle pattern. The non-symmetrical geometry of the specimen due to the thickness reduction of the central zone can lead to some out of plane specimen bending effects. Those effects have been numerically investigated and it is shown that the out of plane specimen displacement before the fracture is less than $1 \mathrm{~mm}$ (confirmed by experiments) which leads to negligible bending effects. A camera is perpendicularly positioned with respect to the plane surface which remains quasi-plane during the test. Consecutive images are recorded by a fast camera and an acquisition of $250 \mathrm{images} / \mathrm{s}$ is chosen. The true in-plane strain components are evaluated by the Digital Image Correlation (DIC) method. A 2D system is then used. Due to the large deformations, the reference image is 
updated at each step of displacement calculation by considering the previous image.

\subsection{Forming limit strains at fracture under non-linear strain paths}

The time-dependent method is relatively efficient for identifying the beginning of fracture. The FL strains at fracture of DP600 sheets under linear strain paths have been identified by the presenting authors [20]. This method is now applied for determining the beginning of fracture and the FL strains at fracture under the two types of non-linear strain path.

The identification of onset of fracture and FL strains at fracture for the pre-displacements of $2.0 \mathrm{~mm}$ in uniaxial tension and $4.0 \mathrm{~mm}$ in equibiaxial stretching are presented here as examples. Figure 5 shows the equivalent strain field of the central area at the time $0.004 \mathrm{~s}$ before fracture with different pre-displacements. The evolution of the equivalent strain at the calculated area $(2.4 \times 2.4 \mathrm{~mm}$ size $)$ for the two pre-displacements are plotted in Figure 6. It can be found that the macroscopic crack (Figure 7 and Figure 8) occurs with an abrupt change of equivalent strain in a very short time $(0.004 \mathrm{~s})$ under each type of non-linear strain paths. The equivalent strain is calculated by assuming volume consistency and is defined by :

$$
\bar{\varepsilon}=\sqrt{\frac{2}{3} \sum_{i, j} \varepsilon_{i j}^{2}}
$$

The volume consistency is debatable after the onset of necking due to the growth of voids in the material but the evolution of equivalent strain is only used to detect the time just before rupture. With the identified time, the major and minor strains of the calculated area at the moment just before the occurrence of macroscopic fracture are used as the FL strains at fracture.

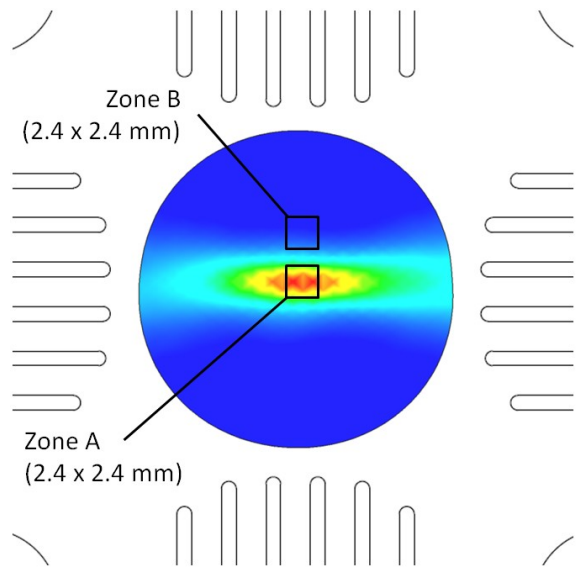

(a) Type 2-A: after $2 \mathrm{~mm}$ uniaxial pre-displacement

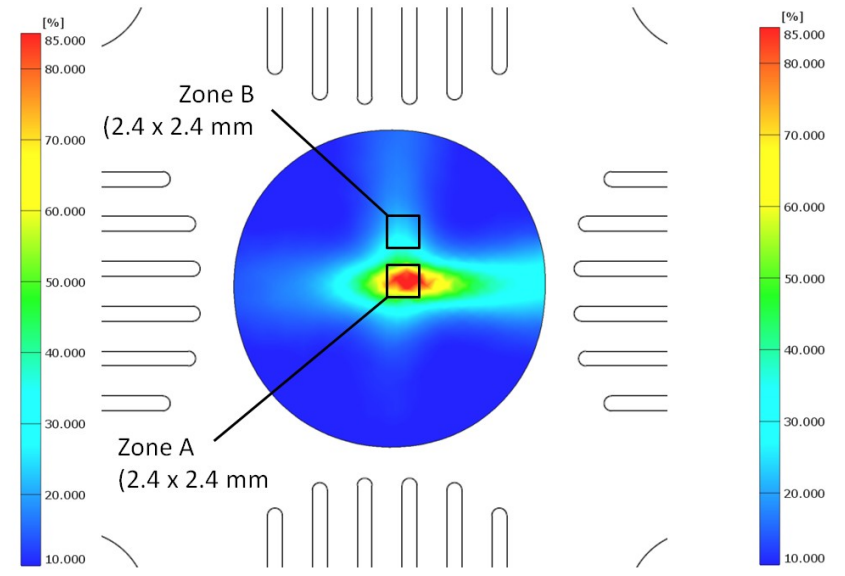

(b) Type 2-B: after $4 \mathrm{~mm}$ equibiaxial pre-displacement

Figure 5: Equivalent strain field of the central area at the time $0.004 \mathrm{~s}$ before the fracture with different predisplacements

For other pre-displacements in uniaxial tension and in equibiaxial stretching, the same method is adopted to identify the FL strains at fracture. Figure 9 shows the FL strains at fracture under different types of non-linear strain path. In this figure, the solid markers and dashed lines represent the FL strains at fracture and the strain paths, respectively. As shown in Figure 9 (a), different pre-displacements in uniaxial tension correspond to different levels of prestrain (see Table 3). After the pre-displacement, the equibiaxial stretching is used in the 


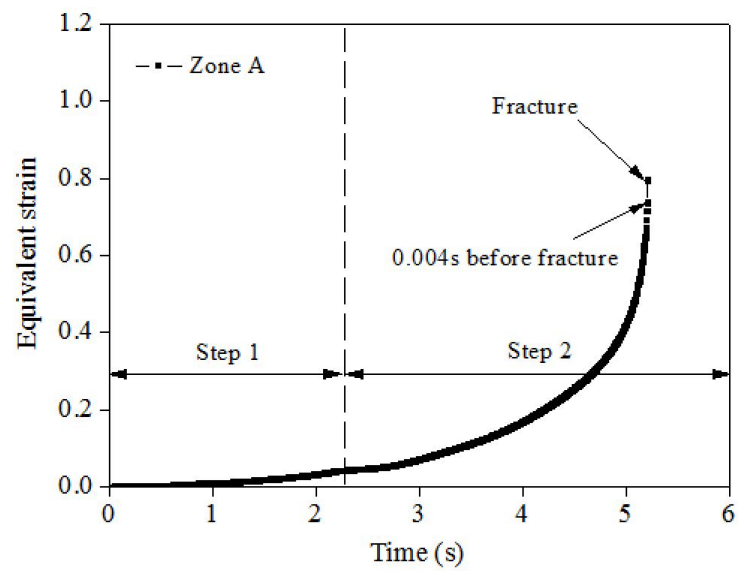

(a) Type 2-A: after $2 \mathrm{~mm}$ uniaxial pre-displacement

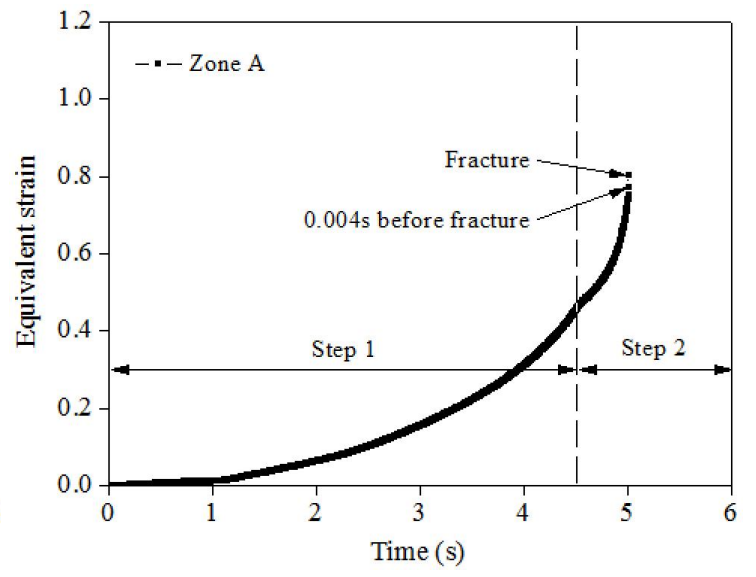

(b) Type 2-B: after $4 \mathrm{~mm}$ equibiaxial pre-displacement

Figure 6: Identification of the onset of fracture under different types of non-linear strain paths

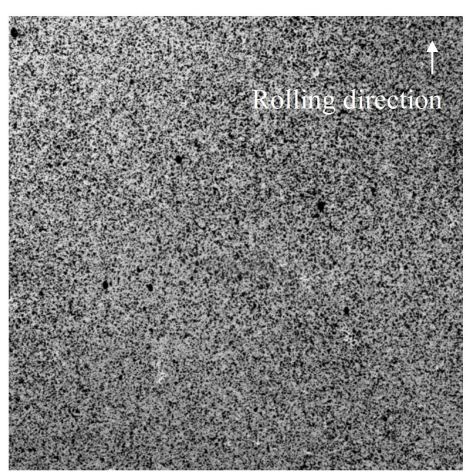

(a) $0.004 \mathrm{~s}$ before fracture

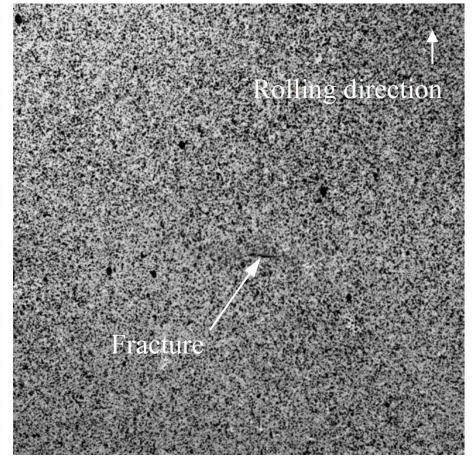

(b) fracture

Figure 7: Specimen surfaces for DP600 sheets with the pre-displacement of $2.0 \mathrm{~mm}$ in uniaxial tension

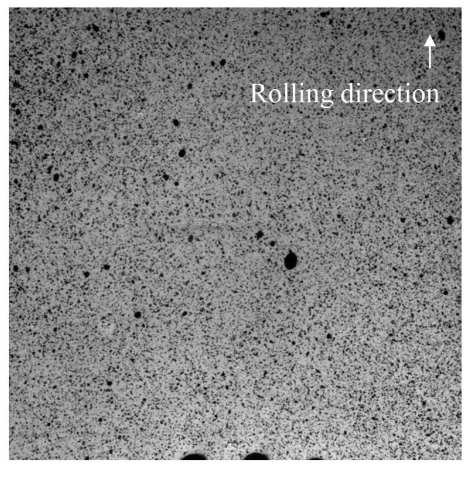

(a) $0.004 \mathrm{~s}$ before fracture

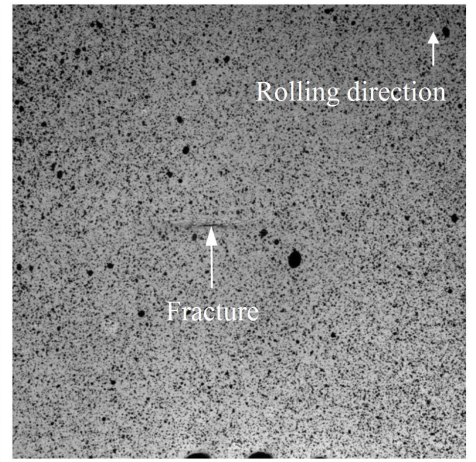

(b) fracture

Figure 8: Specimen surfaces for DP600 sheets with the pre-displacement of $4.0 \mathrm{~mm}$ in equibiaxial stretching 
second step of loading. The transition between the two steps of loading corresponds to an abrupt change of strain path. With increasing the prestrain from $7 \%$ to $27 \%$, the major strain at fracture increases slowly.

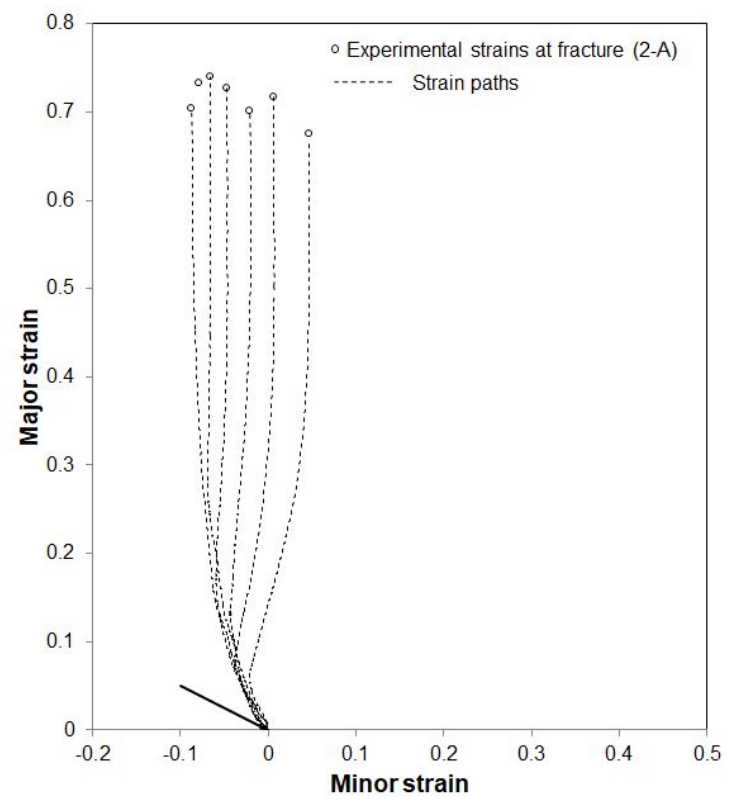

(a) Type 2-A

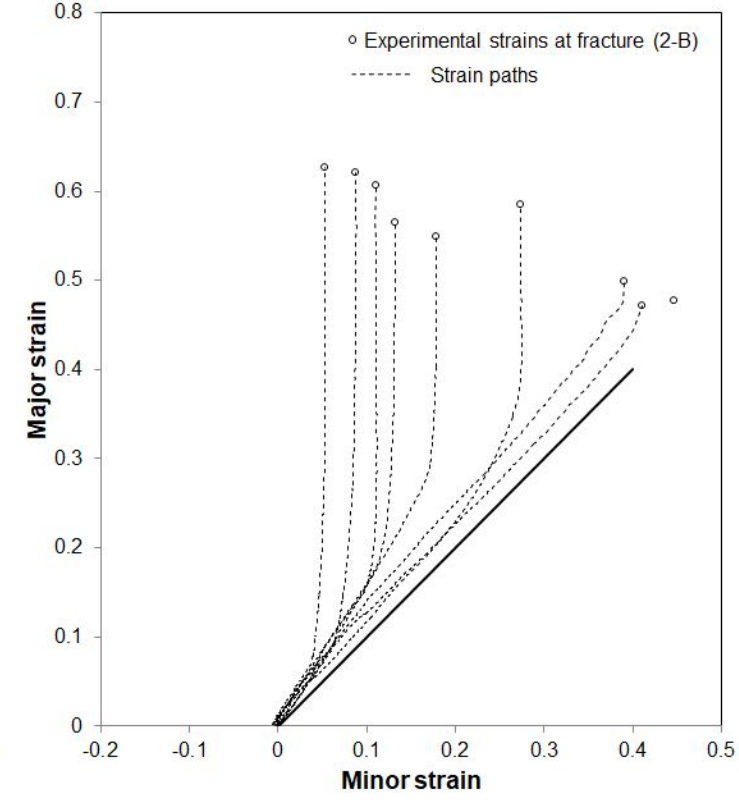

(b) Type 2-B

Figure 9: Forming limit strains at fracture under different non-linear strain paths

Table 3: Major strains at fracture under different pre-displacements in uniaxial tension

\begin{tabular}{cccccc}
\hline Pre-displacement & $2.0 \mathrm{~mm}$ & $2.5 \mathrm{~mm}$ & $3.0 \mathrm{~mm}$ & $3.5 \mathrm{~mm}$ & $4.0 \mathrm{~mm}$ \\
\hline Major strain & $7 \%$ & $9 \%$ & $13 \%$ & $17 \%$ & $27 \%$ \\
\hline
\end{tabular}

As shown in Figure 9 (b), the abrupt change of strain path from equibiaxial stretching to plane strain is obvious for each pre-displacement. Different levels of prestrain in equibiaxial stretching are shown in Table 4. The major strain at fracture decreases with increasing the prestrain from $8 \%$ to $38 \%$. As can be seen in Figure 9 (a), the instability shown in Figure 5 (a) corresponds to a zero extension line. For all the tested paths, before rupture, the minor strain no longer increases and remains constant. Only the major strain grows and a near plane strain state is observed although an equibiaxial stretching is applied.

Table 4: Major strains at fracture under different pre-displacements in equibiaxial stretching

\begin{tabular}{ccccccc}
\hline Pre-displacement & $2.0 \mathrm{~mm}$ & $2.5 \mathrm{~mm}$ & $3.0 \mathrm{~mm}$ & $3.5 \mathrm{~mm}$ & $4.0 \mathrm{~mm}$ & $4.5 \mathrm{~mm}$ \\
\hline Major strain & $8 \%$ & $10 \%$ & $15 \%$ & $22 \%$ & $30 \%$ & $38 \%$ \\
\hline
\end{tabular}

Figure 10 shows the forming limit strains at fracture under linear and non-linear strain paths (Type 2-A and Type 2-B). As described in previous study [20], the forming limit strains at fracture under linear strain paths is fitted by a straight line with $\mathrm{k}=-0.39$ and $\mathrm{A}=0.63$, while those under non-linear strain paths is fitted by a straight line with $\mathrm{k}=-0.49$ and $\mathrm{A}=0.68$. For linear strain paths, the experimental results are in accordance with the ones of Gruben et al. [25], especially for uniaxial and equibiaxial loadings. For plane strain condition, the 
forming limits are lower than the ones of Figure 10(a). In the work of Gruben et al., Nakajima and Marciniak tests were performed. Recently, forming limits at rupture were given for DP600 by Cheng et al. [26] by using Nakajima tests. In this last work, forming limits at fracture for equibiaxial loading are very close to the ones of Figure 10(a). For the other strain paths, forming limits in [26] are systematically lower. As shown in figure 10, the difference between the FLCFs for linear strain paths and non-linear strain paths is small. In other words, the strain path change has very small effect on the forming limit strains at fracture.

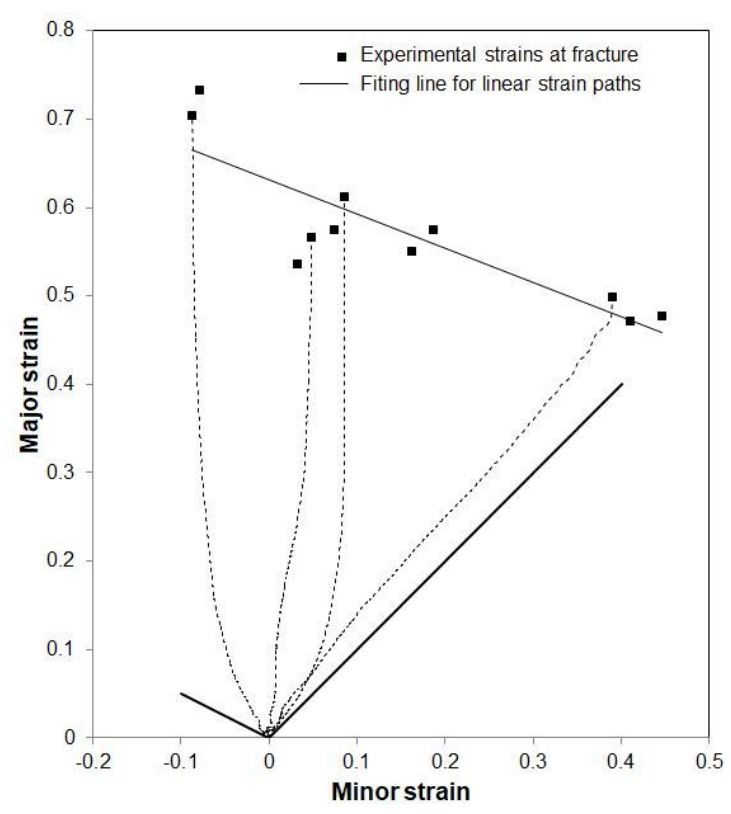

(a) Linear strain paths

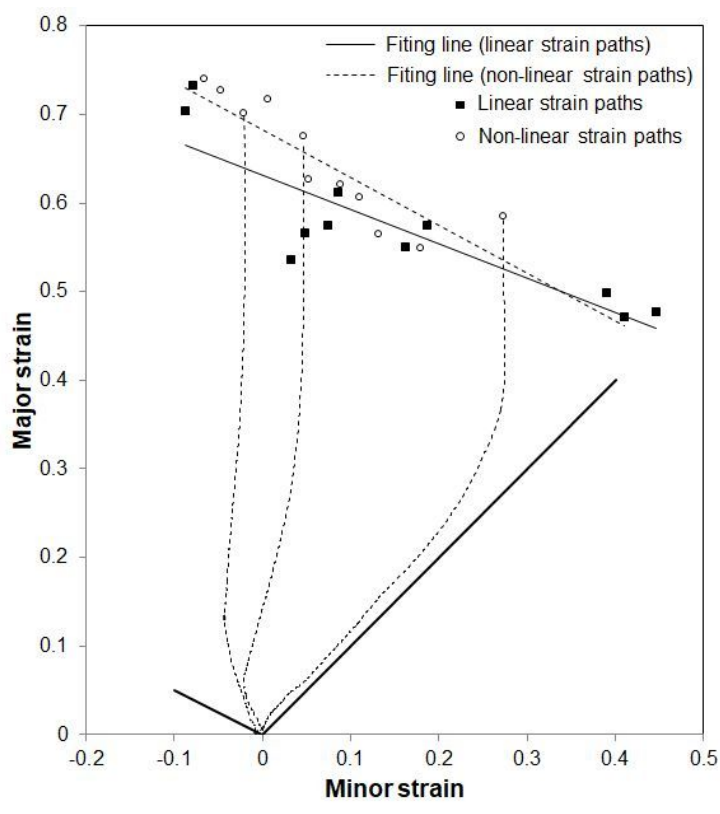

(b) Linear and non-linear strain paths

Figure 10: Comparison of forming limit strains at fracture under different strain paths

\subsection{Forming limit strains at necking under non-linear strain paths}

The critical ratio method was successfully used to identify the FL strains at necking of DP600 sheet metal under linear strain paths [20, 27]. The same method is adopted to determine the FL strains at necking under the two types of non-linear strain paths. In order to apply the critical ratio method, the evolutions of equivalent strain measured respectively in zone A and B (Figure 5) are plotted (Figure 11). In this figure, the onset of necking with the pre-displacement of $2.0 \mathrm{~mm}$ in uniaxial tension and $4.0 \mathrm{~mm}$ in equibiaxial stretching is very clear. When a localized necking appears in the central zone, the equivalent strain in zone A increases abruptly due to the plastic instability, while the equivalent strain in zone B stops any increase and shows a saturation. The moment of the saturation of equivalent strain in zone B is used to define the onset of localized necking. The major and minor strains in zone A associated to this moment define the FL strains at necking. To identify precisely this moment, the ratio of equivalent strain increment between zone A and B is calculated and compared to a critical value. The increment is calculated between each image. The critical value of the equivalent strain increment ratio depends on the position of zone B. For the selected zone B (Figure 5), a value of 8 permits to detect any saturation and then the onset of the plastic instability.

Figure 12 depicts the comparison of FL strains at necking under linear and non-linear strain paths. For the 


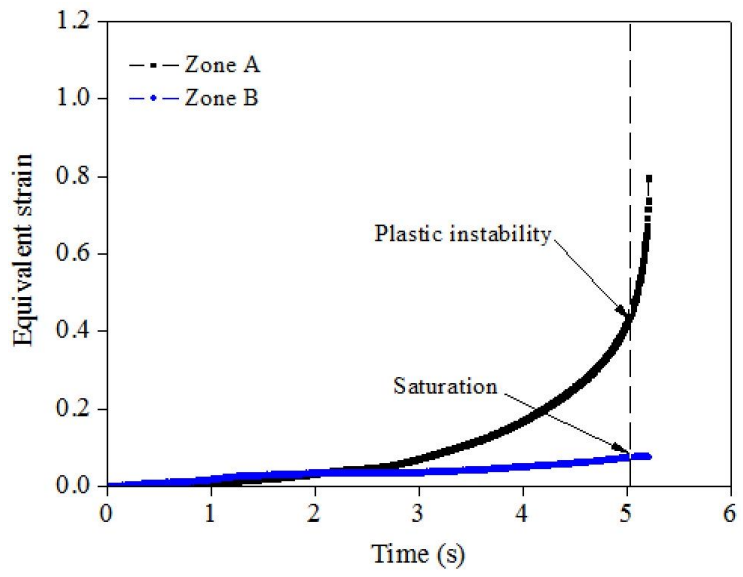

(a) Type 2-A: after $2 \mathrm{~mm}$ uniaxial pre-displacement

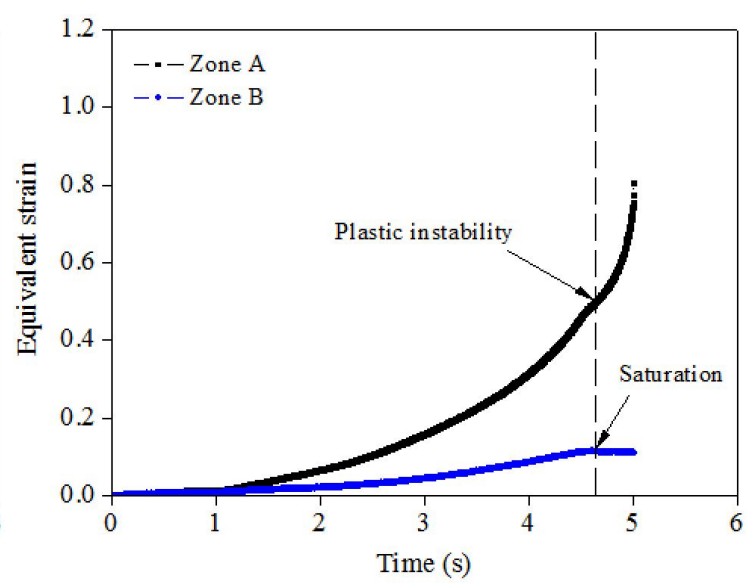

(b) Type 2-B: after $4 \mathrm{~mm}$ equibiaxial pre-displacement

Figure 11: Identification of necking for DP600 sheets under different types of non-linear strain path

type 2-A of non-linear strain path, the FLCN shifts up with respect to the original FLCN under linear strain paths, and a small increase of formability at necking is observed in Figure 12 (a). This phenomenon is also reported by Leotoing et al. [17] for an aluminium alloy sheet and Kuroda et al. [22] for a cold-rolled lowcarbon steel, when the level of prestrain in uniaxial tension is not high. In their researches, a high level of prestrain in uniaxial tension can reduce the formability at necking, which results in an abrupt decrease for the FLCN. In other words, the level of prestrain in uniaxial tension can either improve or reduce the formability at necking. However, as shown in Figure 12 (a), no reduction of formability at necking is observed under a high level of prestrain (major strain beyond 30\%) in uniaxial tension. Therefore, it can be concluded that for the DP600 sheet metal, the prestrain in uniaxial tension improves the formability at necking under the type 2-A of non-linear strain path.

As shown in Figure 12 (b), the FLCN under type 2-B shifts to the down comparing with the original FLCN under linear strain paths. The same results are obtained by Graf and Hosford [6]. For small prestrain (8\% or $10 \%$ ) in equibiaxial stretching, there is no obvious difference between the FLCNs under linear strain paths and non-linear strain paths.

\section{Numerical simulation}

\subsection{Numerical model}

As shown in Figure 13, a predictive model based on the optimized cruciform geometry has been proposed by the finite element $(\mathrm{FE})$ method. The same displacement ratios than the experimental ones are applied along the two perpendicular directions to follow different strain paths. Displacements are applied at the ends of the two arms of the specimen at a distance of $80 \mathrm{~mm}$ far from the central point. For linear strain paths, the same displacement is imposed on each arm. For non-linear strain paths, the displacement values are given in table 2 for the step 1. The FE simulations are produced by the commercial software ABAQUS (implicit solver). Because the cruciform specimen is symmetrical, one-quarter is adopted to save the calculation time. Linear tetrahedral solid elements are used for the mesh. A refined mesh with the size of $0.25 \mathrm{~mm}$ is defined in the central area. 


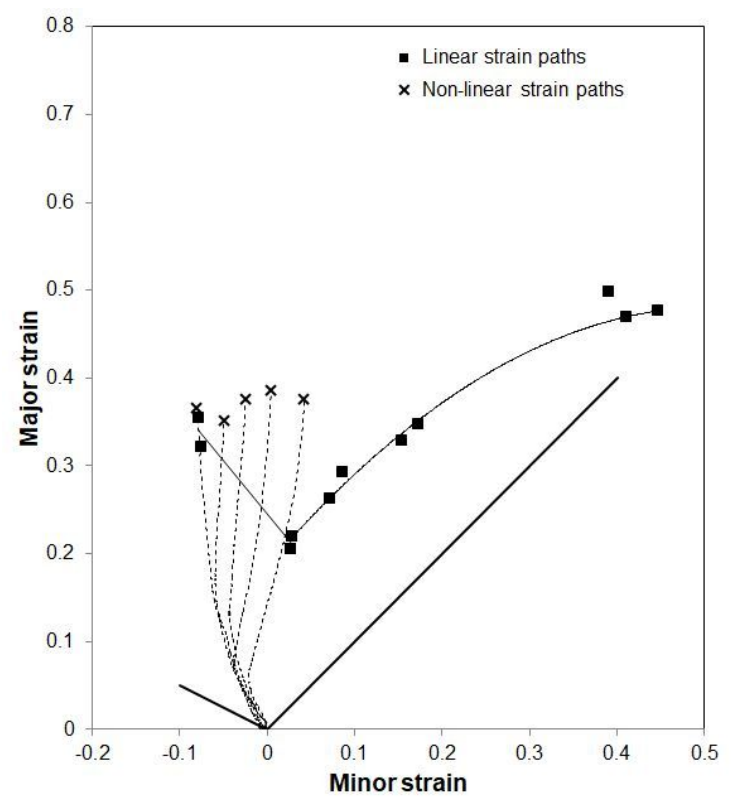

(a) Type 2-A

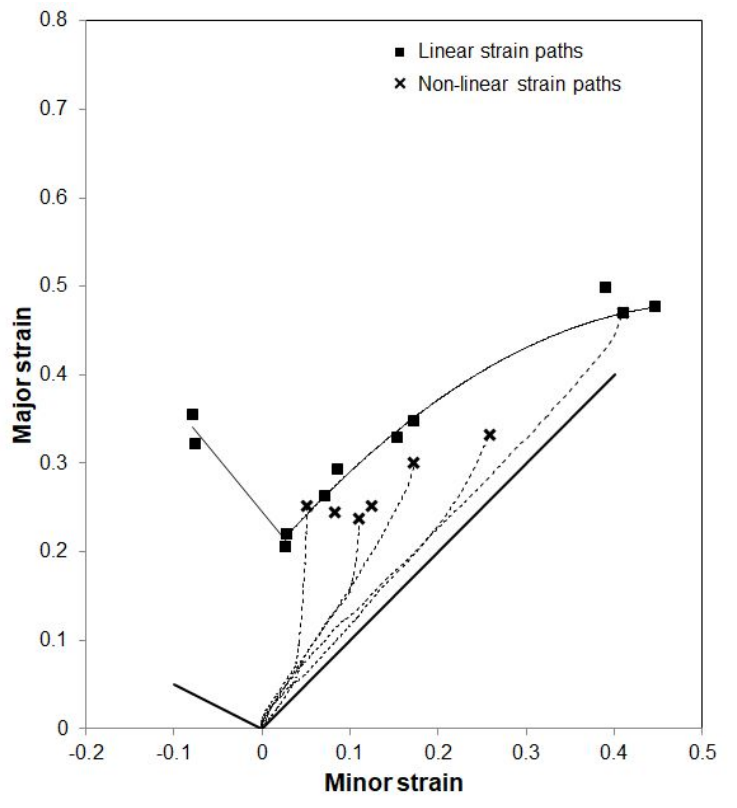

(b) Type 2-B

Figure 12: Comparison of forming limit strains at necking under different strain paths

The identification of DP600 sheet behaviour under in-plane equibiaxial loadings has been performed in previous work [28] for a strain rate ranging from quasi-static to intermediate strain rate. Based on this work, the material constants and material models used in the present work are briefly recalled hereafter. For the isotropic elasticity, Young's modulus of $200 \mathrm{GPa}$ and Poisson's ratio of 0.3 are considered. For the plastic behaviour, the associated normal flow rule is assumed and Hill48 yield criterion for plane stress condition is used.

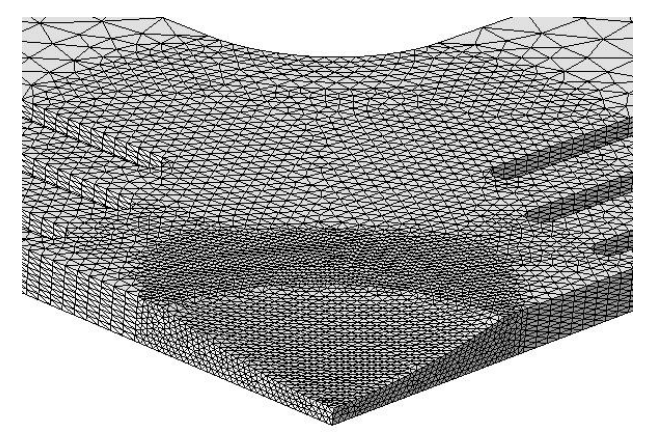

Figure 13: 3D Mesh of the cruciform specimen

As shown in Table 5, the parameters of Hill48 yield criterion for DP600 have been calculated from three anisotropic coefficients proposed by Ozturk et al. [29].

The general strain rate dependent hardening law on the basis of Ludwick formulation [28] has been used:

$$
\bar{\sigma}=\sigma_{0} \dot{\varepsilon}^{m_{1}}+K \varepsilon_{p}^{n} \dot{\varepsilon}^{m_{2}}
$$


Table 5: Lankford's coefficient and Hill48 yield parameters

\begin{tabular}{ccccccccc}
\hline$r_{0}$ & $r_{45}$ & $r_{90}$ & $\mathrm{~F}$ & $\mathrm{G}$ & $\mathrm{H}$ & $\mathrm{L}$ & $\mathrm{M}$ & $\mathrm{N}$ \\
\hline 0.89 & 0.85 & 1.12 & 0.420 & 0.529 & 0.471 & 1.500 & 1.500 & 1.282 \\
\hline
\end{tabular}

The parameters $\sigma_{0}, \mathrm{~K}, \mathrm{n}, m_{1}$ and $m_{2}$ are given in Table 6 .

Table 6: Identified parameters of the rate-dependent hardening law for Hill48 yield criterion [28]

\begin{tabular}{ccccc}
\hline$\sigma_{0}(\mathrm{MPa})$ & $\mathrm{K}(\mathrm{MPa})$ & $\mathrm{n}$ & $m_{1}$ & $m_{2}$ \\
\hline 339.2 & 839.7 & 0.3864 & 0.0052 & 0.0158 \\
\hline
\end{tabular}

\subsection{Ductile fracture criterion}

The Oyane criterion [30] has been used to predict the FLCF of DP600 sheets under linear strain paths by the presenting authors [20]. It should be noted that this criterion is based on an uncoupled ductile model which does not account for the progressive damage of the material. If damage mechanics certainly affect the onset of necking and consequently the fracture strains, uncoupled criteria are easier to implement and to calibrate than microscopic failure criterion. In this study, the Oyane criterion will be used to predict the FLCF under non-linear strain paths. The hydrostatic pressure $\sigma_{h}$ and the equivalent stress $\bar{\sigma}$ are considered in this criterion. Two parameters A and $\mathrm{C}$ need to be identified.

$$
\int_{0}^{\bar{\varepsilon}_{f}}\left(1+\frac{\sigma_{h}}{A \bar{\sigma}}\right) d \bar{\varepsilon}_{p}=C
$$

\subsection{Numerical results}

Figure 14 shows the numerical FLCFs under different strain paths calculated with the Oyane ductile fracture criterion. The parameters $\mathrm{A}$ and $\mathrm{C}$ were identified by minimizing the gap between the experimental fitting line and the fracture forming line for linear strain paths $(A=-1$ and $C=0.45)$ (Figure 14(a)). The same values of $A$ and $\mathrm{C}$ are used to predict the numerical FLCFs under non-linear strain paths (Figure 14(b)). The numerical FLCFs under linear and non-linear strain paths (type 2-A and 2-B) are almost overlapped. This conclusion is in accordance with the experimental results since the same fracture line can be defined for both linear and non-linear strain paths. Besides, it is possible to calibrate the Oyane criterion parameters in order to predict accurately the experimental results under linear and non-linear strain paths. The criterion is validated under a certain range of stress triaxiality $\frac{\sigma_{h}}{\bar{\sigma}}$ (from $1 / 3$ in uniaxial tension to $2 / 3$ in equibiaxial tension). To discuss the validity of the criterion for other strain states, we think that low stress triaxiality values could be obtained with the in-plane biaxial test by applying a tension along one direction and a compression along the other one.

\section{Conclusions}

An optimized cruciform specimen has been used with the in-plane biaxial tensile test to identify the FL strains at fracture and necking of DP600 sheets under non-linear strain paths. Two types of non-linear strain paths without unloading are used in the tests. Some conclusions are obtained: 


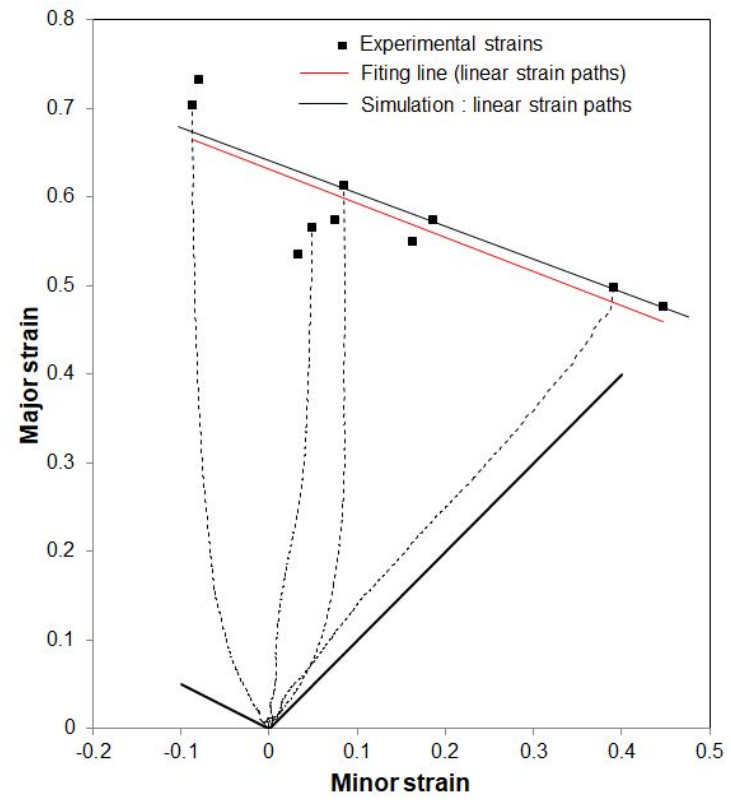

(a) Linear strain paths

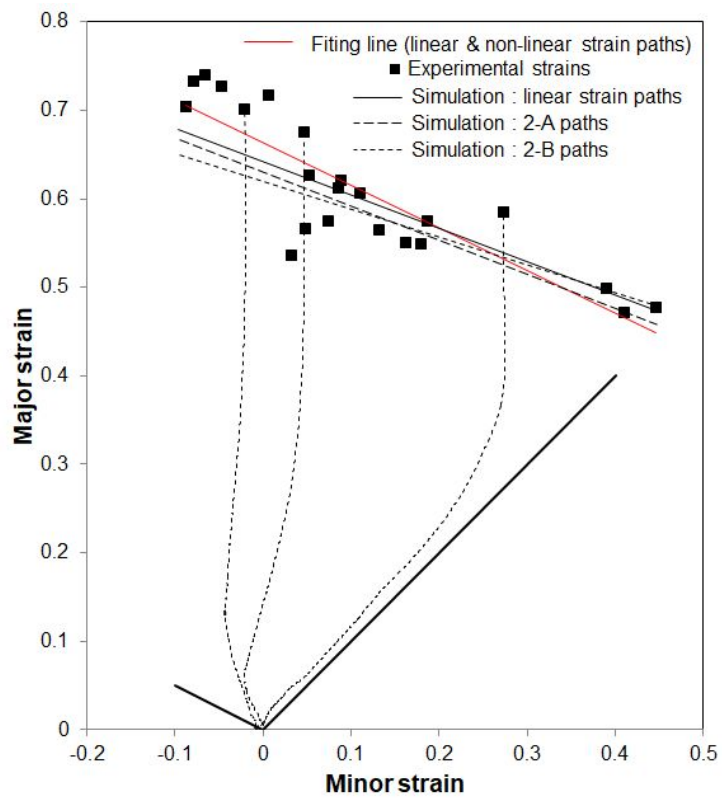

(b) Non-linear strain paths

Figure 14: Prediction of forming limits at fracture for DP600

(1) The FL strains at fracture of DP600 sheets under non-linear strain paths can be fitted by a straight line. The difference between the experimental FLCFs under linear and nonlinear strain paths is very small, which indicates that the strain path change has very small effect on the experimental FLCF.

(2) The prestrain in uniaxial tension followed by equibiaxial stretching can increase the level of FL strain at necking of DP600 sheets, while the prestrain in equibiaxial stretching followed by plane-strain tension can decrease it.

(3) The numerical FLCFs calculated by the Oyane criterion predict well the experimental FL strains at fracture under linear and non-linear strain paths. The strain path change has almost no effect on the prediction of FLCF. Calibration of the Oyane criterion can be performed from simple tests, under proportional loadings.

\section{References}

[1] P. Eyckens, B. Belkassem, C. Henrard, J. Gu, H. Sol, A.M. Habraken, J.R. Duflou, A. Van Bael, and P. Van Hoote. Strain evolution in the single point incremental forming process: digital image correlation measurement and finite element prediction. International Journal of Material Forming, 4:55-71, 2011.

[2] A.B. Da Rocha, F. Barlat, and J.M. Jalinier. Prediction of the forming limit diagrams of anisotropic sheets in linear and non-linear loading. Materials Science and Engineering, 68(2):151-164, 1985.

[3] K. Yoshida, T. Kuwabara, and M. Kuroda. Path-dependence of the forming limit stresses in a sheet metal. International Journal of Plasticity, 23(3):361-384, 2007.

[4] X. Song, L. Leotoing, D. Guines, and E. Ragneau. Investigation of the forming limit strains at fracture of AA5086 sheets using an in-plane biaxial tensile test. Engineering Fracture Mechanics, 163:130-140, 2016. 
[5] H. Ishigaki. Deformation analysis of large sized panels in the press shop, pages 315-339. Springer US, Boston, MA, 1978.

[6] A. Graf and W. Hosford. The influence of strain-path changes on forming limit diagrams of Al $6111 \mathrm{~T} 4$. International Journal of Mechanical Sciences, 36(10):897-910, 1994.

[7] T.B. Stoughton and J.W. Yoon. Path independent forming limits in strain and stress spaces. International Journal of Solids and Structures, 49(25):3616-3625, 2012.

[8] A. Graf and W. Hosford. Effect of changing strain paths on forming limit diagrams of Al 2008-T4. Metallurgical Transactions A, 24A:2503-2512, 1993.

[9] W. Volk, H. Hoffmann, J. Suh, and J. Kim. Failure prediction for nonlinear strain paths in sheet metal forming. CIRP Annals-Manufacturing Technology, 61(1):259-262, 2012.

[10] C.L. Chow, L.G. Yu, W.H. Tai, and M.Y. Demeri. Prediction of forming limit diagrams for AL6111-T4 under non-proportional loading. International Journal of Mechanical Sciences, 43(2):471-486, 2001.

[11] R. Uppaluri, N.V. Reddy, and P.M. Dixit. An analytical approach for the prediction of forming limit curves subjected to combined strain paths. International Journal of Mechanical Sciences, 53(5):365-373, 2011.

[12] J. Cao, H. Yao, A. Karafillis, and M.C. Boyce. Prediction of localized thinning in sheet metal using a general anisotropic yield criterion. International Journal of Plasticity, 16(9):1105-1129, 2000.

[13] R. Arrieux, C. Bedrin, and M. Boivin. Determination of an intrinsic forming limit stress diagram for isotropic sheets. In Proceedings of the 12th IDDRG Congress, volume 2, pages 61-71, 1982.

[14] T.B. Stoughton. A general forming limit criterion for sheet metal forming. International Journal of Mechanical Sciences, 42(1):1-27, 2000.

[15] T.B. Stoughton and J.W. Yoon. Sheet metal formability analysis for anisotropic materials under nonproportional loading. International journal of mechanical sciences, 47(12):1972-2002, 2005.

[16] M.C. Butuc, J.J. Gracio, and A.B. Da Rocha. An experimental and theoretical analysis on the application of stress-based forming limit criterion. International Journal of Mechanical Sciences, 48(4):414-429, 2006.

[17] L. Leotoing and D. Guines. Investigations of the effect of strain path changes on forming limit curves using an in-plane biaxial tensile test. International Journal of Mechanical Sciences, 99:21-28, 2015.

[18] T. Kuwabara, S. Ikeda, and K. Kuroda. Measurement and analysis of differential work hardening in coldrolled steel sheet under biaxial tension. Journal of Materials Processing Technology, 80-81:517-523, 1998.

[19] L. Leotoing, D. Guines, I. Zidane, and E. Ragneau. Cruciform shape benefits for experimental and numerical evaluation of sheet metal formability. Journal of Materials Processing Technology, 213(6):856-863, 2013.

[20] X. Song, L. Leotoing, D. Guines, and E. Ragneau. Characterization of forming limits at fracture with an optimized cruciform specimen: Application to DP600 steel sheets. International Journal of Mechanical Sciences, 126:35-43, 2017. 
[21] A. Graf and W. Hosford. Calculations of forming limit diagrams for changing strain paths. Metallurgical Transactions A, 24(11):2497-2501, 1993.

[22] M. Kuroda and V. Tvergaard. Effect of strain path change on limits to ductility of anisotropic metal sheets. International Journal of Mechanical Sciences, 42(5):867-887, 2000.

[23] K. Isik, M.B. Silva, A.E. Tekkaya, and P.A.F. Martins. Formability limits by fracture in sheet metal forming. Journal of Materials Processing Technology, 214(8):1557-1565, 2014.

[24] X. Song, L. Leotoing, D. Guines, and E. Ragneau. Identification of forming limits at fracture of dp600 sheet metal under linear and unloaded non-linear strain paths. In Procedia Engineering, volume 207, pages 562-567, 2017.

[25] G. Gruben, D. Vsysochinskiy, T. Coudert, A. Reyes, and O.-G. Lademo. Determination of ductile fracture parameters of a dual-phase steel by optical measurements. Strain, 49:221-232, 2013.

[26] C. Cheng, B. Meng, J.Q. Han, M. Wan, X.D. Wu, and R. Zhao. A modified lou-huh model for characterization of ductile fracture of dp590 sheet. Materials and Design, 118:89-98, 2017.

[27] C. Zhang, L. Leotoing, G. Zhao, D. Guines, and E. Ragneau. A comparative study of different necking criteria for numerical and experimental prediction of flcs. Journal of Materials Engineering and Performance, 20(6):1036-1042, 2011.

[28] W. Liu, D. Guines, L. Leotoing, and E. Ragneau. Identification of strain rate-dependent mechanical behaviour of DP600 under in-plane biaxial loadings. Materials Science and Engineering: A, 676:366376, 2016.

[29] F. Ozturk, S. Toros, and S. Kilic. Effects of anisotropic yield functions on prediction of forming limit diagrams of DP600 advanced high strength steel. Procedia Engineering, 81:760-765, 2014.

[30] M. Oyane, T. Sato, K. Okimoto, and S. Shima. Criteria for ductile fracture and their applications. Journal of Mechanical Working Technology, 4(1):65-81, 1980. 